\title{
OPEN Sex pilus specific bacteriophage to drive bacterial population towards antibiotic sensitivity
}

Received: 20 July 2018

Accepted: 24 July 2019

Published online: 30 August 2019

\author{
Joan Colom ${ }^{1}$, Diego Batista ${ }^{2}$, Abiyad Baig ${ }^{1}$, Ying Tang ${ }^{1}$, Siyang Liu ${ }^{1}$, Fangzhong Yuan ${ }^{1}$, \\ Aouatif Belkhiri ${ }^{1}$, Lucas Marcelino ${ }^{2}$, Fernanda Barbosa ${ }^{2}$, Marcela Rubio ${ }^{2}$, Robert Atterbury ${ }^{1}$, \\ Angelo Berchieri ${ }^{2} \&$ Paul Barrow $^{1}$
}

Antimicrobial resistance (AMR) is now a major global problem largely resulting from the overuse of antibiotics in humans and livestock. In some AMR bacteria, resistance is encoded by conjugative plasmids expressing sex-pili that can readily spread resistance through bacterial populations. The aim of this study was to use sex pilus-specific (SPS) phage to reduce the carriage of AMR plasmids. Here, we demonstrate that SPS phage can kill AMR Escherichia coli and select for AMR plasmid loss in vitro. For the first time, we also demonstrate that SPS phage can both prevent the spread of AMR Salmonella Enteritidis infection in chickens and shift the bacterial population towards antibiotic sensitivity.

Antimicrobial resistance (AMR) results from both regulated and unregulated use of antibiotics and other chemotherapeutic agents for disease treatment in both human and veterinary medicine, and as growth promoters in livestock rearing ${ }^{1,2}$. Transmission of resistant bacteria is exacerbated by globalisation of the animal and food trades, and increased travel $^{3}$. However, modern medicine relies heavily on their use and they currently remain essential for many medical interventions including cardiac and bowel surgery, neonatal care and cancer treatment. AMR is now seen as one of the most severe global threats to health ${ }^{4}$.

The economic cost of AMR is difficult to judge, but the negative effects include medication costs and reduced Gross Domestic Product (GDP) estimated at between 2-3.5\% globally. The yearly cost to the United States (US) health system has been estimated at US \$21-\$34 billion dollars, and more than 8 million additional days in hospital $^{4}$. It is estimated that by 2050 , the global cost could reach $\$ 65$ trillion and could lead to 10 million deaths per year ${ }^{4}$. Individual patients have already died from untreatable bacterial infections as a result of AMR . $^{5}$

Global antibiotic consumption increased by $36 \%$ from 2000 to 2010 with $76 \%$ of this in the BRICS countries, which includes Brazil ${ }^{6}$. There are now signs of increasing controls on antibiotic use in many countries where historically there has been none ${ }^{7}$ but the frequency of resistance to key chemotherapeutic antibiotics in pathogens such as Salmonella enterica and Staphylococcus aureus may nevertheless reach $100 \%$ of strains in such countries $^{8-10}$. Transmissible resistance to colistin, one of the last resort antibiotics, has also been reported in humans, pigs and meat in China ${ }^{11}$ and several other countries.

AMR in indicator organisms such as E. coli in pigs and chickens is common in many countries ${ }^{9,12}$, with transmission from livestock to human, mainly via the food chain ${ }^{12,13}$. The recent O'Neill report highlighted the role of E. coli, both as a commensal and pathogen, as a significant driver of resistance ${ }^{4}$. Much resistance in this organism is plasmid-mediated and transmissible, including resistance to antimicrobials which 20 years ago were chromosomally located such as quinolones and colistin. In the absence of antibiotic selective pressure, plasmid-mediated resistance is frequently associated with reduced fitness in bacteria ${ }^{14}$.

The World Health Organization (WHO) recently published a list of pathogens prioritised in order of greatest threat to human health and for which new antibiotics are urgently required ${ }^{15}$. This includes carbapenem-resistant and ESBL-producing members of the Enterobacteriaceae, especially E. coli and Klebsiella pneumoniae ${ }^{15}$. The $\mathrm{WHO}$ has also called for a comprehensive strategy to address $\mathrm{AMR}^{4,16}$, with tighter national regulation on antimicrobial use. However, even with such controls the problem of resistance will remain acute for decades. Additional

\footnotetext{
${ }^{1}$ School of Veterinary Medicine and Science, University of Nottingham, Sutton Bonington, Leicestershire, LE12 5RD, UK. ${ }^{2}$ School of Agricultural and Veterinary Sciences, São Paulo State University (FCAV/UNESP), São Paulo, 14884-900, Brazil. Correspondence and requests for materials should be addressed to P.B. (email: Paul.barrow@ nottingham.ac.uk)
} 


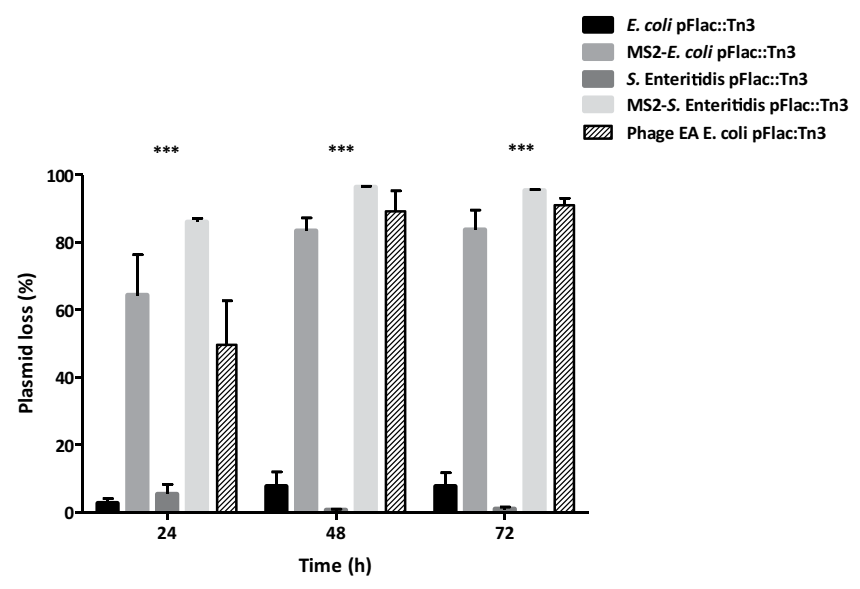

Figure 1. Phage MS2 and phage EA influence on de-repressed plasmid pFlac::Tn3 populations over time. Bars show mean values of three independent experiments \pm standard error. Significance was calculated using the Two-way ANOVA with Bonferroni post-tests. $* * * \mathrm{P}<0.001$.

recommended approaches to countering AMR include improvements in diagnosis, the identification of new drugs, and the development of alternative approaches to tackle the problem, including the use of phages ${ }^{16}$.

Under carefully controlled conditions, lytic phages have been shown to be highly effective in controlling or preventing a variety of infections ${ }^{17,18}$ including E. coli septicaemia in mice, chicken and colostrum-deprived calves $^{19-21}$ and intestinal colonisation by Salmonella ${ }^{22}$ and Campylobacter ${ }^{23,24}$. Most phages attach to surface receptors which are also virulence determinants such as capsules ${ }^{19}$ or lipopolysaccharide ${ }^{20}$. Some phages are known to attach to a range of self-transmissible plasmid-mediated sex pili, which differ in their specificity according to the plasmid incompatibility (Inc) group ${ }^{25,26}$. Sex pilus-specific (SPS) phages, particularly incompatibility group $\mathrm{F}$-specific phages, have been used in bacterial genetics for the identification of bacterial cells possessing the $\mathrm{F}$ factor and IncF related plasmids ${ }^{27}$. Interestingly, the level of pili expression varies depending on the plasmid. Some of the plasmids in the F group are classified as derepressed and constitutively express F pili in all conditions ${ }^{28}$. However, other natural IncF plasmids are more repressed and will only express the conjugative pili at low levels and under certain conditions ${ }^{29}$. The application of SPS phages should not only kill bacteria harbouring such plasmids, but any phage-resistant mutants should have lost the plasmid. This could result in bacteria becoming antibiotic sensitive, if the plasmid harboured AMR genes. We have used a model system comprising the Flac plasmid in a laboratory E. coli strain, and the SPS RNA phage MS2 $2^{30}$ to study plasmid loss in vitro. We also transferred the plasmid to a Salmonella enterica ser. Enteritidis strain to study phage activity and plasmid loss in vivo in a chicken model of infection. Although the F plasmid is unusual as a completely de-repressed plasmid it acts as a good model for this approach to addressing AMR particularly since many wild-type plasmids also show varying degrees of de-repression ${ }^{31}$.

\section{Results}

The F-specific phage MS2 select for loss of F-like plasmids. The effect of the SPS phage MS2 and the LPS-specific phage EA on plasmid population dynamics was initially tested with a highly self-transmissible Flacplasmid model using an E. coli J62 carrying the Flac-plasmid tagged with Tn3 $\left(\mathrm{Amp}^{\mathrm{R}}\right)$. For that, MS2 was added to a late mid-exponential culture of this strain at a multiplicity of infection (MOI) of 10 and incubated for $24 \mathrm{~h}$. After incubation, $64 \pm 12.0 \%$ of the bacterial population had lost the plasmid in contrast to a bacterial culture incubated without phage where the loss was $2.5 \pm 1.5 \%$ (Fig. 1$)(\mathrm{P}<0.001)$. Similar results were observed with the LPS phage EA, reducing a $49.7 \pm 12.9 \%$ the presence of plasmid (Fig. $1, \mathrm{P}<0.001$ ). Because it has been shown that the presence of large transmissible plasmids can sometimes reduce the growth rate of bacteria in the absence of the environmental conditions that select for the plasmid maintenance ${ }^{14,32}$. As such, continued passage in the presence of MS2 was expected to increase the percentage of the plasmid-negative derivatives. The results showed that after 48 and $72 \mathrm{~h}$ plasmid loss increased to $83 \pm 3.9 \%$ under the selective pressure of phage MS2 and remained very low when the phage was absent $(7.5 \pm 4.3 \%)$. Very similar results were observed when the same experiment was performed with phage EA, where plasmid carriage was reduced by up to $91 \pm 2.1$ (Fig. $1, \mathrm{P}<0.001$ ). Despite these similarities, only the SPS-phage MS2 was able to reduce plasmid carriage in a S. Enteritidis P125109 Flac::Tn3 (Fig. 1, P < 0.001). This is a consequence of the type of receptor used by the phage. A LPS phage will be restricted to strains closely related to each other while the SPS-phage, using the pilus encoded by the plasmid will not have restrictions in strain specificity. This highlights the advantage of using SPS phage over classic phage using LPS as a receptor to attach to the bacterial host.

Characterisation of phage-resistant bacteria. Phage MS2 activity on the highly transmissible F plasmid derivative Flac::Tn 3 resulted in an increased fitness of phage-resistant, plasmid-free derivatives above that of phage-resistant, plasmid-containing mutants. Two randomly-selected phage-resistant E. coli J62 Flac:: Tn3 derivatives (R3 and R4) were characterised further. In both mutants MS2 adsorption was almost non-existant, being significantly reduced an $84.6 \%(\mathrm{R} 3)$ and $92.4 \%$ (R4) after 14 min compared to the parental Flac:: $\operatorname{Tn} 3$ (Table 1). 


\begin{tabular}{|l|l|l|l|l|}
\hline Plasmid & MS2 sensitivity & $\begin{array}{l}\text { Transfer rate } \\
\text { (\%) }\end{array}$ & $\begin{array}{l}\text { MS2 adsorption } \\
\text { (\%)* }\end{array}$ & $\begin{array}{l}\text { Reduction in } \\
\text { adsorption (\%) }\end{array}$ \\
\hline Flac::Tn3 (parent) & YES & $95.7 \pm 3.5$ & $86.8 \pm 5.1$ & 0 \\
\hline Flac::Tn3 R3 & NO & $0.0 \pm 0.0$ & $13.4 \pm 10.1$ & 84.6 \\
\hline Flac::Tn3 R4 & NO & $0.0 \pm 0.0$ & $6.6 \pm 6.6$ & 92.4 \\
\hline
\end{tabular}

Table 1. Plasmid transfer rate of MS2 phage-resistant Flac::Tn3 E. coli strains. *Adsorption after 14 minutes in contact with the strains carrying plasmids. The values presented are the mean of three independent experiments $(\mathrm{n}=3) \pm$ standard error.

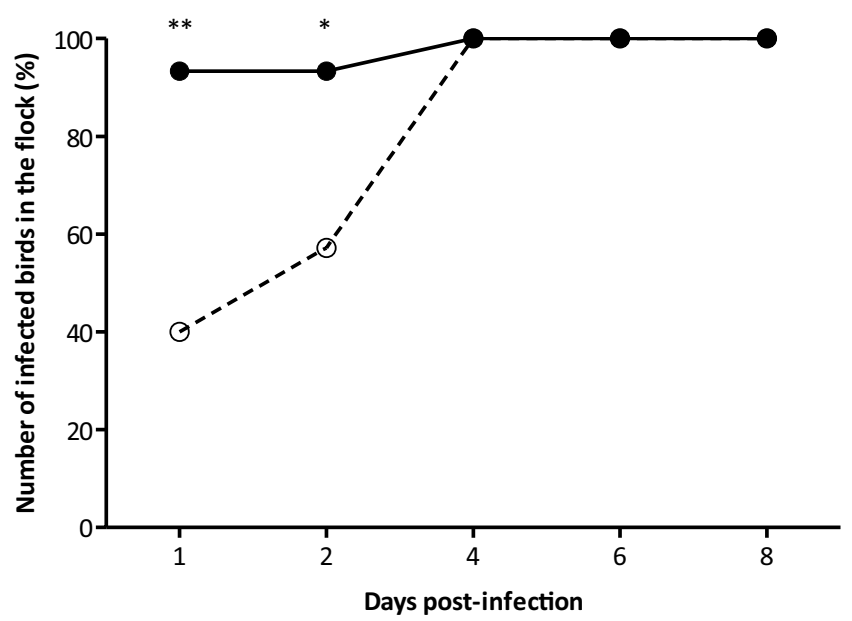

Figure 2. S. Enteritidis P125109 Flac::Tn3 spread in whole chicken flock. Phage MS2 treated group (O) and control animals $(\bullet)$. Values represent mean proportion of infected birds in the flock $(n=15)$. Significance was calculated using Fisher's exact test. $* \mathrm{P}<0.05 ; * * \mathrm{P}<0.01$.

Neither of these mutants could transfer the plasmid and ampicillin resistance to E. coli 711 Rif $^{\mathrm{R}}$ (Table 1). The new phenotype may be explained by substantial changes in sex-pilus structure or expression. Full sequencing of the R4 mutant revealed a mis-sense mutation in the traJ gene (Supplementary Data 1). It is known that the traJ gene is a positive regulator involved in the expression of the transfer genes in plasmids ${ }^{33}$. Therefore, a missense mutation in it would lead to a reduced or inexistent conjugation ability as reflected by the results obtained in this section.

Phage MS2 drives Salmonella Enteritidis towards plasmid loss and antibiotic sensitivity during infection of chickens. The effect of phage MS2 administration on plasmid loss from a $S$. Enteritidis from which the F-like virulence plasmid had been eliminated ${ }^{30}$ and into which Flac:: $\operatorname{Tn} 3$ was transferred, was studied during transmission of the strain through a group of young chickens. A standard seeder-bird experimental design was used in which a small number of birds within a group are infected, and transmission to in-contact (spreader) birds is monitored at intervals ${ }^{34}$. Although this tends to show transmission over a period of weeks in birds of more than few days old, it was expected that transmission between a small group of newly-hatched chickens would be very rapid when not treated with phage, as occurred (Fig. 2).

The results showed that MS2 controlled effectively the dissemination of the S. Enteritidis Flac::Tn3 through the in-contact, spreader birds for two days post-infection with only $40 \%$ and $57 \%$ of the phage-treated birds infected on days 1 and 2 in comparison with $93 \%$ in the untreated birds at this time $(\mathrm{P}<0.01, \mathrm{P}<0.05)$. However, by 4 days post-infection the infection levels were the same in both groups (Fig. 2). In addition, 8 birds from the control, untreated group required euthanasia due to the severity of disease; whereas none of the birds in the phage-treated group exhibited clinical signs of infection. The percentage of $S$. Enteritidis recovered from the birds, which also harboured the plasmid was statistically different between the phage-treated and control groups.

From day 1 , the level of plasmid carriage in the phage-treated seeder birds was very low, with a proportion of plasmid-free colonies ranging between $83.2 \pm 5.4 \%$ to $100 \pm 0.0 \%$ during the experiment $(\mathrm{P}<0.01)$ (Fig. 3). In contrast, the level of plasmid carriage in the control group was high throughout the experiment, although the frequency of plasmid-free bacteria increased from $2.1 \pm 2.1 \%$ to $36.6 \pm 8.6 \%$ between days 1 and 6 post-infection (Fig. 3). However, the presence of phage MS2 was associated with a significantly higher proportion of plasmid-free bacteria $(\mathrm{P}<0.01)$. It is clear then that phage MS2 activity in the intestine accelerates this natural process.

The results corresponded directly with the bacterial and plasmid population dynamics in the spreader birds. The proportion of plasmid free colonies was similar in both groups during the first two days of the experiment (Fig. 4). The low spread rate of $S$. Enteritidis in the phage-treated group reduced the difference in plasmid free $S$. Enteritidis between groups at this time. However, the situation changed completely after day 4 post-infection when $S$. Enteritidis spread was similar in both groups (Fig. 2). At that point, only plasmid-free $S$. Enteritidis was detected in the treatment group, while the proportion of plasmid-free bacteria reached a maximum of $35.0 \pm 4.2 \%$ 


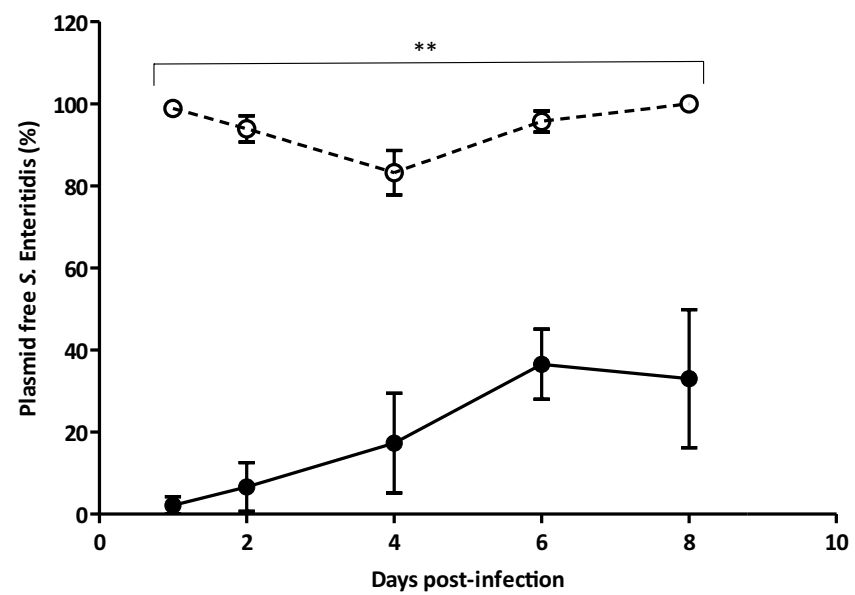

Figure 3. Plasmid-free presence of $S$. Enteritidis in seeder birds. Phage MS2 treated group $(O)$ and control animals $(\bullet)$.Values represent mean proportion of plasmid free $S$. Enteritidis $(n=5) \pm$ standard error. Significance was calculated using the Mann Whitney $\mathrm{U}$ test. $* * \mathrm{P}<0.01$.

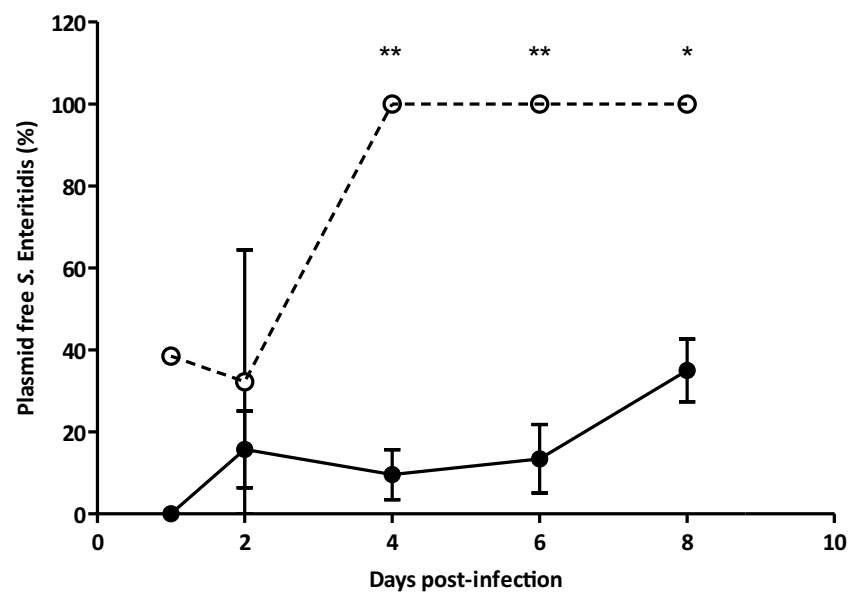

Figure 4. Plasmid-free population of $S$. Enteritidis in Spreader birds. Phage MS2 treated group $(O)$ and control animals $(\bullet)$. Values represent mean proportion of plasmid free $S$. Enteritidis \pm standard error $(n=10)$. Significance was calculated using Mann Whitney $\mathrm{U}$ test. $* * \mathrm{P}<0.01, * \mathrm{P}<0.05$.

at day 8 post-infection in the control group (Fig. $4, \mathrm{P}<0.01$ ). Similar results were observed for the populations of $S$. Enteritidis found in the caecum of the animals at days 4 and 8 post-infection (Fig. $5 \mathrm{P}<0.05)$. In the treated group, MS2 phage counts in the caeca were $6.9 \pm 0.33$ and $6.8 \pm 0.13 \log _{10} \mathrm{PFU} / \mathrm{mL}$ at days 4 and 8 post-infection.

All plasmid-free derivatives were sensitive to ampicillin, and unlike in the in vitro studies, the few plasmid-carrying $S$. Enteritidis recovered from the treatment group remained sensitive to phage MS2. Therefore, the selective pressure exerted by the phage MS2 shifted the Salmonella population in the seeder birds to be plasmid-free. This new population spread through the flock, infecting the spreader birds and, perhaps as a result of greater metabolic fitness, overtook any plasmid-carrying bacteria resistant to MS2 phage.

F-like plasmid characterization. The present and a previous study ${ }^{35,36}$ concentrated on plasmids which are relatively de-repressed and thus highly susceptible to sex pilus-specific phage. It was important to explore the effect of phage on wild-type plasmids which show varying degrees of repression for the expression of sex-pilus ${ }^{32,37}$.

The majority of AMR-plasmids isolated in recent years belong to Incompatibility group $\mathrm{F}^{38,39}$. The incompatibility group of the plasmids from a collection of wild-type AMR E. coli strains isolated from chickens ${ }^{29}$ was determined by $\mathrm{PCR}^{40}$. All the plasmids belonged to incompatibility group F (Table 2). Most AMR-plasmids are self-transmissible but at very variable rates both in vitro and in vivo although the latter is generally several orders of magnitude lower ${ }^{41,42}$. To have a better understanding of these plasmid dynamics, the presence of the repressor fin $O$ gene of the correct size was detected by PCR and correlated with the self-transmissibility rate calculated for all of them (Table 2).

As expected, the de-repressed plasmid Flac::Tn3 had a very high transfer rate. In this plasmid, the repressor FinO is inactive due to an insertion sequence IS $3 a$ in $f_{i n} \mathrm{O}^{43}$. This leads to a constitutive production of conjugative pili which promotes F-plasmid transmission. Despite the presence of an intact fin $O$ gene being detected in all the remaining F-like plasmids, four of them had almost the same transfer rates as Flac::Tn3. Only the plasmids pF16 


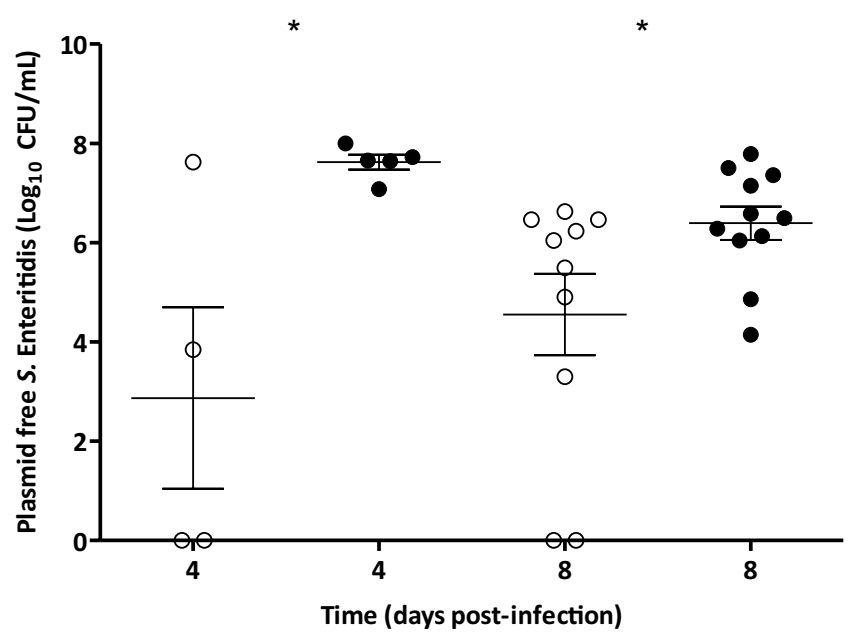

Figure 5. Plasmid-free $S$. Enteritidis in the caecum of Spreader birds. Phage MS2 treated group (O) and control animals $(\bullet)$, values represent concentration of plasmid free $S$. Enteritidis. The average for each group $(-) \pm$ standard error is also shown $(\mathrm{n}=5,10)$. Significance was calculated using Mann Whitney U test. $* \mathrm{P}<0.05$

\begin{tabular}{|c|c|c|}
\hline E. coli AMR-Plasmid & Genotype & Transfer rate (\%) \\
\hline pFlac:: $\operatorname{Tn} 3$ & F-like, $f i n O^{-}$ & $95.7 \pm 3.5$ \\
\hline $\mathrm{pF} 16$ & F-like, $f i n O^{+}$ & $20.3 \pm 0.7$ \\
\hline $\mathrm{pF} 18$ & F-like, $f_{i n O^{+}}$ & $80.2 \pm 1.1$ \\
\hline $\mathrm{pF} 21$ & F-like, $f_{i n O^{+}}$ & $23.0 \pm 0.9$ \\
\hline $\mathrm{pF} 26$ & F-like, $f_{i n} \mathrm{O}^{+}$ & $99.5 \pm 0.5$ \\
\hline $\mathrm{pF} 27$ & F-like, $f_{i n} \mathrm{O}^{+}$ & $100 \pm 0.0$ \\
\hline pF28 & F-like, $f_{i n O^{+}}$ & $96.8 \pm 0.7$ \\
\hline
\end{tabular}

Table 2. Plasmid transfer rate after conjugation with E. coli J62 Rif ${ }^{\mathrm{R}}$. Values are presented as the mean of three replicates $(n=3) \pm$ standard error.

and pF21 showed a degree of reduced conjugative ability. Therefore, the presence of an apparently functional FinO does not preclude relatively high transfer rates indicating a more complex control of sex- pilus expression and conjugation than expected.

Phage MS2 host range. We tested the ability of phage MS2 to infect the wild-type E. coli chicken strains carrying the semi-repressed AMR-plasmids which, of necessity, was tested in broth cultures because clear plaques would not form on bacterial lawns as a result of the low proportion of cells expression sex-pili (Fig. 5). This situation leads to a mixed bacterial population containing phage-resistant and phage-sensitive clones. In such conditions, phage MS2 plaques could not be observed on lawns of the host in top agar, because the resistant population would mask an developing plaques. Therefore, the only way to assess phage MS2 infectivity was to check the production of new virions in broth cultures of the strains. Figure 6 shows the initial and final phage concentration after $24 \mathrm{~h}$ incubation with the host strains.

Although all the plasmids were F-like, phage MS2 replication was observed only in strains carrying plasmids pF16 and pF21, with phage multiplication levels similar to those found in E. coli J62 Flac::Tn3 (Fig. 6). The reason is the presence of $\mathrm{F}$ sex-pilus which is a characteristic common to the IncF/MOBF12 plasmid group ${ }^{44}$. However, slight changes in phage MS2 receptor TraA protein, might explain the lack of infection in some of the strains isolated from chickens.

Phylogenetic analysis based on traA. For the phylogenetic analysis, the nucleotide sequences of $\operatorname{tra} A$ from the F-plasmids from this study were compared with the nucleotide sequences of traA from published F-plasmids from E. coli and E. faecalis (Fig. S1). The reference F-plasmid NC_002483.1 was used as positive control for phage MS2 infection. The phylogeny showed that the plasmids pF2 6 and pF2 8 were closely related and clustered together in clade 1 . The reference F-plasmid NC_002483.1 was in clade 2, closer to the clade 3 which included pF21. The pF16 was most distantly related to pF26, pF28 and pF21 and was part of the clade 4. The multiple sequence comparison of the nucleotide sequence of traA showed that the reference published F-plasmid NC_002438.1 shared highest identity (99.73\%) with the pF21 and was least identical to pF26 and pF28 (95.9\%) (Fig. S2). 


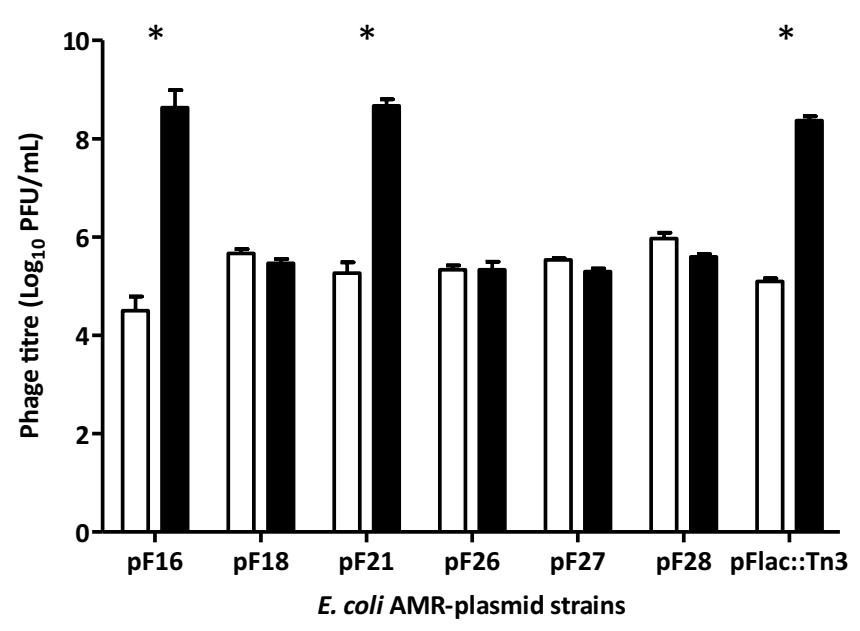

Figure 6. Phage MS2 replication in AMR-plasmid E. coli strains. White bars represent MS2 titre at time $0 \mathrm{~h}$, while black bars show the titre after $24 \mathrm{~h}$ incubation at $37^{\circ} \mathrm{C}$ with shacking. E. coli J62 Flac:: $\operatorname{Tn} 3$ was set as a positive control for phage MS2 replication. All values are the mean of three independent replicates \pm standard error $(n=3)$. Significance was calculated using Mann Whitney $U$ test. $* P<0.05$.

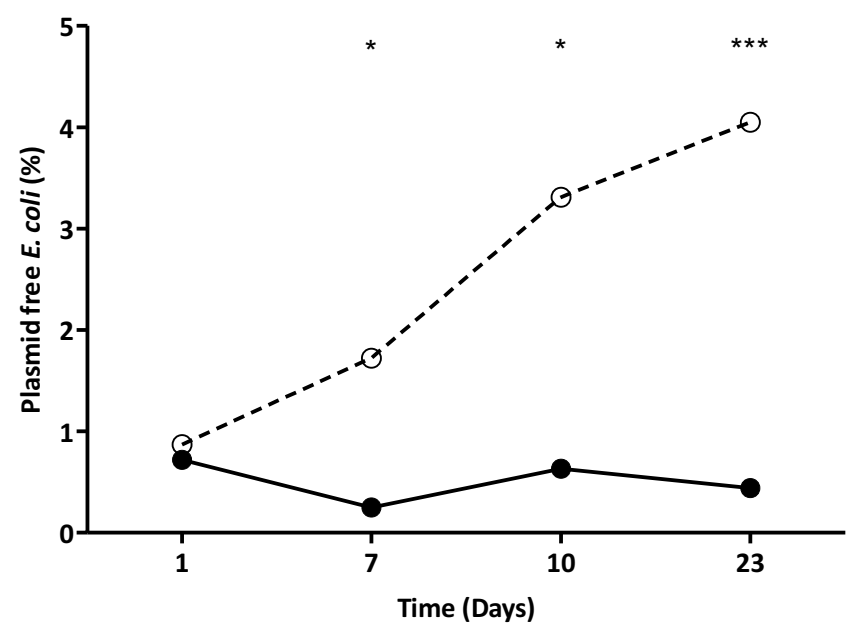

Figure 7. Phage MS2 effect on repressed plasmid pF21 presence over time. Phage MS2 treated group $(O)$ and untreated control $(\bullet)$. Significance was calculated using Fisher's exact test. $* \mathrm{P}<0.05$; $* * \mathrm{P}<0.01$.

The F-specific phage MS2 selects for loss of repressed F-like plasmids. The effect of passage of E. coli pF21 in broth with the presence of MS2 phage was monitored over several days, with the result that selection for plasmid loss was also observed (Fig. 7). Although the plasmid loss increased from $0.9 \%$ to only $4.1 \%$ after 23 days in contact with MS2 phage, the reduction in plasmid population was ten times higher than in the untreated group $(0.4 \%, \mathrm{P}<0.001)$. In a bacterial population carrying a more repressed plasmid, fewer bacterial cells will express sex-pili and be sensitive to MS2 phage.

The F-specific phage MS2 blocks bacterial conjugation. To see whether the presence of phage MS2 was able to block plasmid transfer, phage was added during a conjugation in vitro. As expected, the phage was able to stop transmission of Flac::Tn3, reducing the transfer rate by $99.95 \%$ (Table 3). For the repressed plasmids pF16 and pF21, the effect of the phage was even greater as conjugation was completely undetectable.

\section{Discussion}

We have shown that lytic bacteriophages, which specifically use plasmid-associated sex pili as attachment points, not only have the potential to kill bacteria harbouring plasmids which are relatively highly de-repressed but also select for plasmid loss and block plasmid transmission. With a de-repressed plasmid, phage application led to an over $80 \%$ plasmid loss from a $S$. Enteritidis strain both in vitro and in the intestines in young chickens.

The effect of sex pilus-specific phages on plasmid stability, especially AMR-plasmids has been studied previously $y^{35,36}$. However, to the best of our knowledge this is the first time that this effect has been demonstrated in vivo. Previous reports suggested that a small number of phage of different specificities might be sufficient to cover the major replication types of AMR-plasmid ${ }^{35}$. Nevertheless, this might be over-optimistic as there are significant 


\begin{tabular}{|l|l|l|l|}
\hline \multirow{2}{*}{ Plasmid } & MS2 phage & $\begin{array}{l}\text { Transfer rate } \\
\text { (\%)* }\end{array}$ & $\begin{array}{l}\text { Reduction in } \\
\text { transfer rate (\%) }\end{array}$ \\
\hline \multirow{2}{*}{ Flac::Tn3 } & - & $95.7 \pm 3.5$ & 0 \\
\cline { 2 - 4 } & MOI 10 & $0.05 \pm 0.04$ & 99.95 \\
\hline \multirow{2}{*}{ pF16 } & - & $20.3 \pm 0.7$ & 0 \\
\cline { 2 - 4 } & MOI 10 & $0 \pm 0.0$ & 100 \\
\hline \multirow{2}{*}{ pF21 } & - & $23.0 \pm 0.9$ & 0 \\
\cline { 2 - 4 } & MOI 10 & $0 \pm 0.0$ & 100 \\
\hline
\end{tabular}

Table 3. Plasmid transfer rate after conjugation with E. coli 711 Rif $^{\mathrm{R}}$ with and without MS2 phage. *Values are presented as the mean of three replicates $(n=3) \pm$ standard error.

differences in sex-pilus structure even within the F-like plasmid group ${ }^{45}$. The traA relatedness of our collection of F-plasmids with the published F-plasmid sequences suggests that those published plasmids which grouped with the pF21, pF16 and NC_002438 represent a sex-pilus structure which phage MS2 will be able to infect. Therefore, phage MS2 would only infect conjugative F-plasmids carrying traA sequences closely related to clades 2,3 and $4^{44}$. This suggests that a phage cocktail will be necessary to tackle different plasmids within the F-like plasmids.

The group of Jalasvuori has shown that phage PRD1, which attaches to the sex-pilus of IncP, N and W plasmids ${ }^{46}$, was able to select for plasmid loss ${ }^{35,36}$. As in that study, a small proportion of phage-resistant but nevertheless antibiotic resistant (plasmid-containing), strains arose as a result of the selective pressure of MS2 phage. The three Flac::Tn3 derivatives analysed here were unable to conjugate and showed complete immunity to phage MS2 adsorption. Genomic analysis of MS2 phage-resistant mutant R4 revealed mutations in traJ region, which encodes the activator of the major transfer operon in the F-plasmid ${ }^{47}$. Thus, phage activity either eliminated the antibiotic resistance plasmid or eliminated the capacity to transmit the plasmid further. Phage MS2 induced extensive loss of the de-repressed Flac:: $\mathrm{Tn} 3$ in vitro and also a significant loss of the F-like pF21 plasmid from an AMR E. coli isolated from chickens. This effect was enhanced by extended contact of the plasmid carrying strains and MS2 phage, which was also observed for a phage PRD1 reported previously ${ }^{36}$. The lower rate of wild-type pF21 plasmid loss may be explained by its more repressed nature. In such repressed systems, where fewer bacterial population express sex-pili the effective MOI may be greater than for a completely de-repressed plasmid. However, plasmid transfer to a recipient population is epidemic with new recipients showing a burst of sex-pilus production resulting from momentary de-repression following low intracellularly concentrations of FinO and Fin $^{48}$. Therefore, the presence of a sex pilus-specific phage in the environment at the time of conjugation activity could prevent plasmid transmission even if these are highly repressed. This hypothesis was confirmed, as MS2 phage completely blocked transmission of pF16 and pF21. Similar findings were obtained with the de-repressed RP4 plasmid ${ }^{35,36}$. This suggests that sex pilus-specific phage administration might reduce epidemic spread of de-repressed and repressed plasmids.

Although the results suggest that phage administration might reduce also plasmid spread, this approach certainly shows the effect of SPS phage on plasmid carriage during normal bacterial growth, both in vitro and in vivo.

We studied the effect of MS2 phage administration on the carriage and spread of a Salmonella containing the de-repressed Flac::Tn3 in a chicken flock. The in vivo trial showed that in the intestines of very young chickens, where Salmonella may colonise nearly all regions of the gut ${ }^{49}$, the administration of phage MS2 reduced the transmission of the Salmonella with the plasmid between birds by direct reduction in the numbers of plasmid-carrying bacteria. There was notable plasmid loss in both the birds which were inoculated directly (seeder) and in those where the infection occurred by contact with the directly infected birds (spreaders). Interestingly, a progressive loss of plasmid in the untreated animals occurred, although this was much lower than in the phage-treated birds. This natural plasmid loss is likely to be a consequence of the high metabolic cost of a constitutive expression of the transfer apparatus ${ }^{48}$ in the absence of any evolutionary pressure selecting for maintenance of the plasmid. In contrast to the results obtained in vitro, no phage-resistant Salmonella mutants were recovered which nevertheless continued to carry the plasmid. It is possible that the metabolic burden of the $100 \mathrm{~kb}$ F-plasmid ${ }^{50}$ made very difficult the competition of the plasmid-containing, phage-resistant mutants against the plasmid-free Salmonella, which overtook and colonized the gut much faster.

These results indicate that the use of SPS phage has a three-fold advantage against AMR bacteria where the resistance is plasmid-mediated, namely (i) the killing effect in environments in vitro and in vivo where good contact can be made between phage and sex-pilus, particularly where in vivo gut contents are fairly liquid; (ii) the selection of plasmid-free derivatives which could outgrow the remaining phage-resistant AMR mutants; (iii) the reduced ability of the phage-resistant AMR mutants to self-transmit their plasmids.

This group envisages that sex pilus-specific phages might be applied under two sets of conditions, either in a population (animal or human) or in an individual. In the former situation the present results suggest that, in the absence of antibiotic administration and pressure, widespread phage use should drive bacterial evolution towards plasmid and AMR loss as the bacteria multiply in and spread between individuals. Thus, despite continuing concerns over phage application in the environment where phage-resistance could develop this is one situation where it does not appear to be a major concern since the phage-resistant derivatives are desirable. In individual treatment, such as a septicaemia case, bacterial numbers may be reduced by treatment with sex-pilus specific phage such that the host's immunity may be able to deal with it, as suggested previously ${ }^{20,21}$. The advantage conferred by plasmid loss should result in the gradual replacement by antibiotic sensitive bacterial derivative cells, which if transmitted to other individuals should proliferate at the expense of AMR strains. 


\section{Methods and Materials}

Bacterial strains, culture media. E. coli $\mathrm{J} 62$ lac pro trp his pFlac:: $\operatorname{Tn} 3\left(\mathrm{Amp}^{\mathrm{R}}\right)$ and Salmonella Enteritidis $\mathrm{P} 125109^{51}$ from which the virulence plasmid had been eliminated ${ }^{52}$ and the $\mathrm{pFlac}: \mathrm{Tn} 3$ introduced $\left(\mathrm{Amp}^{\mathrm{R}}\right)$ were used as host for phage MS2. A rifampicin resistant mutant of the Salmonella strain $\left(\mathrm{Amp}^{\mathrm{R}}\right.$, Rif ${ }^{\mathrm{R}}$ ) was used for the in vivo experiments. A collection of plasmid-containing wild-type AMR E. coli strains isolated from poultry $\mathrm{y}^{37}$ were selected for host range, phage MS2 sensitivity and plasmid loss experiments (Table S1). E. coli J62 Rif ${ }^{\mathrm{R}}$ was used as recipient strain for plasmid transfer rate assessment.

Luria Bertani (LB) broth and agar (1\%, Sigma) was used for routine culture of the strains. Viable counts of E. coli J62 pFlac::Tn3 $\left(\mathrm{Amp}^{\mathrm{R}}\right)$ and AMR strains were determined by plating dilutions on MacConkey agar (Sigma) with or without antibiotics. The same was done for $S$. Enteritidis P125109 pFlac::Tn3 (Amp ${ }^{\mathrm{R}}, \mathrm{Rif}^{\mathrm{R}}$ ) counts, using Brilliant green agar (Sigma) supplemented with the appropriate antibiotic. For dilution purposes Phosphate-Buffered saline (PBS) buffer was used.

Plasmid incompatibility group determination. The presence of F-like plasmids was determined by PCR following a previously described method $^{40}$ with slight modifications. A set of primers were used to recognise four specific regions of replicons that are representative of plasmids belonging to the Incompatibility F group (Table S2). The multiplex and the singleplex PCR cycling conditions consisted of an annealing temperature of $60^{\circ} \mathrm{C}$ and $52^{\circ} \mathrm{C}$ for $30 \mathrm{sec}$ respectively. For both reactions, the initial denaturation step was performed at $94^{\circ} \mathrm{C}$ for $5 \mathrm{~min}$, denaturation at $94^{\circ} \mathrm{C}$ for $1 \mathrm{~min}$ and an elongation and final extension at $72{ }^{\circ} \mathrm{C}$ at $1 \mathrm{~min}$ and $5 \mathrm{~min}$ respectively. The presence of the repressor $f i n O$ was also detected by PCR. For that, primers were designed using Primer3 based on the genomic sequence NC_002128.1 (Table S2). Similar cycling conditions as for the multiplex PCR were used except that the extension time was run for 40 seconds. Amplicons were then analysed on 1\% agarose gel.

Bacteriophage and propagation. Liquid lysates of phage $\mathrm{MS}^{30}$ and phage EA $(10 \mathrm{ml})$ were prepared by inoculating mid-exponential cultures of the plasmid-carrying strain $E$. coli 562 at a multiplicity of infection (MOI) of 0.1 . The mixture was then incubated overnight at $37^{\circ} \mathrm{C}$ with shaking at $150 \mathrm{rpm}$. After incubation, the lysate was centrifuged at $10,000 \times \mathrm{g}$ for $10 \mathrm{~min}$ and filtered through a $0.45 \mu \mathrm{m}$ syringe filter (Sartorius). In all cases, phage titres were determined by spotting $10 \mu \mathrm{l}$ of decimal dilutions onto LB plates using the double agar layer method ${ }^{53}$.

Double agar layer method ${ }^{53}$.

Phage adsorption. An E. coli J62 pFlac:: Tn 3 culture at mid-exponential phase was infected with phage MS2 at an MOI of 0.1 . The adsorption rate was determined by taking samples every $2 \mathrm{~min}$ for up to $14 \mathrm{~min}$. At each time point, adsorbed phage were removed by centrifugation at 13,000 $\times$ g. After this, the supernatant was filtered using $0.45 \mu \mathrm{m}$ filter (Millipore) and unbound phage were plated on LB agar overlays containing $0.1 \mathrm{~mL}$ of the host strain. The plates were then incubated overnight at $37^{\circ} \mathrm{C}$ before enumeration.

MS2 host range. Ten millilitre LB broth aliquots were inoculated with $100 \mu \mathrm{l}$ of the relevant wild-type AMR E. coli strain or E. coli $\mathrm{J} 62 \mathrm{pFlac::Tn} 3$ overnight cultures. The mixtures were then incubated $2-3 \mathrm{~h}$ at $37^{\circ} \mathrm{C}$ with shaking until the mid-exponential phase was reached. At that point, MS2 phage was inoculated at a final concentration of $10^{5} \mathrm{PFU} / \mathrm{mL}$, giving a final MOI of 0.001 . One millilitre samples were taken at time 0 and $24 \mathrm{~h}$ and filtered through $0.45 \mu \mathrm{m}$ syringe filters to check phage titre ${ }^{53}$. Significant increases between initial $(0 \mathrm{~h})$ and final $(24 \mathrm{~h})$ phage titre indicated phage replication in the host strain.

Effect of MS2 phage during conjugation. Overnight LB broth cultures of the recipient E. coli J62 Rif ${ }^{R}$ and donor wild-type AMR E. coli strains and E. coli J62 pFlac::Tn 3 were prepared. For the conjugation $5 \mu \mathrm{L}$ of both donor and recipient strain were diluted in the same $5 \mathrm{~mL}$ LB broth aliquot with or without MS2 phage at a final MOI of 10. The mixture was then incubated overnight at $37^{\circ} \mathrm{C}$ without shaking. After incubation, dilutions were plated on MacConkey agar supplemented with rifampicin $(100 \mu \mathrm{g} / \mathrm{mL})$ to enumerate the recipient strain. Similarly, for the trans-conjugant counts dilutions were plated on MacConkey agar rifampicin (75 ug/mL) and an appropriate antibiotic for the donor plasmid. The plasmid transfer rate was calculated as:

$$
\frac{\text { Trans-conjugant }\left(\frac{\mathrm{CFU}}{\mathrm{mL}}\right)}{\text { Recepient }\left(\frac{\mathrm{CFU}}{\mathrm{mL}}\right)}
$$

Plasmid population kinetics with the F plasmid. An overnight LB broth culture of E. coli J62 pFlac:: $: \operatorname{Tn} 3$ was diluted $1 / 100$ in two $10 \mathrm{~mL}$ aliquots of LB broth. The fresh cultures were incubated for $2 \mathrm{~h}$ at $37^{\circ} \mathrm{C}$ with shaking. After incubation, one of the aliquots was inoculated with $100 \mu \mathrm{L}$ of a MS2 phage preparation to give a final MOI of 10. Both cultures were then incubated with shaking for $24 \mathrm{~h}$ at $37^{\circ} \mathrm{C}$. The cultures were again diluted $1 / 100$ in fresh LB broth and $100 \mu \mathrm{L}$ of MS2 phage preparation was added to treatment group as before. This process was repeated again at 48 and $72 \mathrm{~h}$. Samples were taken each $24 \mathrm{~h}$ and plasmid loss was studied. For this, serial dilutions were plated on MacConkey agar and 100 colonies were replicate-plated using MacConkey agar without and with ampicillin $(100 \mu \mathrm{g} / \mathrm{mL})$. The percentage of plasmid loss was then calculated as:

$$
\left(\frac{\text { Ampicillin sensitive colonies }}{\text { Total number of colonies }}\right) \times 100 \text {. }
$$


Plasmid population kinetics with a F-like repressed plasmid. An overnight LB broth culture of the $E$. coli strain carrying the $\mathrm{pF} 21$ plasmid $\left(\mathrm{Sm}^{\mathrm{R}}\right)$ was diluted $1 / 100$ in two $10 \mathrm{ml}$ volumes of LB broth. To one of those, a $100 \mu \mathrm{L}$ of MS2 phage preparation was inoculated to give a final MOI of 10 . Both cultures were incubated with shaking for $24 \mathrm{~h}$ at $37^{\circ} \mathrm{C}$ and were then diluted $1 / 100$ in fresh LB broth adding $100 \mu \mathrm{L}$ MS2 preparation as before. This process was continued daily for 23 days. At $0,1,7,10$ and 23 days after incubation a diluted aliquot of each culture was plated on 5 MacConkey plates, aiming for a count of 200 well separated colonies on each plate. These plates were incubated overnight and replica-plated to MacConkey plates with or without streptomycin $(100 \mu \mathrm{g} / \mathrm{ml})$ to which the strain was resistant. After incubation colonies which had lost the antibiotic resistance were identified and plasmid loss rate was calculated as mentioned above.

Characterization of AMR-plasmid isolates resistant to MS2 phage. E. coli J62 pFlac::Tn3 colonies which were phage-resistant after MS2 phage treatment were characterized. The presence of plasmid was tested by PCR with F-like plasmid specific primers ${ }^{40}$. Resistance to ampicillin was also tested by plating on MacConkey agar supplemented with ampicillin $(100 \mu \mathrm{g} / \mathrm{mL})$. Phage MS2 adsorption was performed as described previously ${ }^{54}$ and studies of plasmid transfer rate were done as described above.

Genomic and phylogenetic analysis based on traA. Raw sequence reads generated as FastQ file for each F-plasmid were assembled de novo using SPAdes (v3.6.2) (5) $^{55}$ The contigs with size more than 1000 bases were extracted and further analysed. The nucleotide sequence of traA from the reference published F-plasmid from E. coli K-12, NC_002438.1 was used as a query in BLAST $+{ }^{56}$ against the genome sequences of the F-plasmids. The nucleotide sequences of $\operatorname{traA}$ from the corresponding F-plasmids were extracted using the start and end positions from the BLAST output. The nucleotide alignments were produced by ClustalW (CLUSTAL 2.1) ${ }^{57}$. The maximum likelihood phylogenetic analysis was performed using the generalized time-reversible (GTR) model to infer nucleotide evolution with FastTree ${ }^{58}$. The phylogeny was visualised using FigTree (http://tree.bio.ed.ac. uk/software/figtree/).

Chicken experiment. Chicken experiments were designed following the ARRIVE guidelines (https://www. nc3rs.org.uk/arrive-guidelines) and approved by the University of Nottingham Animal Welfare and Ethical Review Body (Approval Non UK 0006 Phage-mediated loss of antimicrobial resistance) and by the FCAV, UNESP ethical review panel. All the experiments were performed in accordance with the rules set by the University of Nottingham Animal Welfare and Ethical Review Body and by the FCAV, UNESP ethical review panel.

Two groups of 15 newly hatched chicks were housed separately in cages $(95 \times 95 \times 30 \mathrm{~cm})$ and provided with chicken mash and water ad libitum. They were placed in clean rooms at ambient temperature and provided with heat lamps. All birds were swabbed on receipt to check for freedom from Salmonella. The swabs were incubated in selenite broth and plated on to plain and rifampicin supplemented $(100 \mu \mathrm{g} / \mathrm{mL})$ Brilliant green agar.

Two groups of 15 newly hatched chickens (Ross 308) were infected with S. Enteritidis P125109 pFlac::Tn3 $\left(A m p^{\mathrm{R}}\right.$ Rif $\left.^{\mathrm{R}}\right)$. One group (Treatment) was treated with MS2 phage, while the other control group was untreated. The birds were kept for 8 days and housed in separated rooms with appropriate precautions taken to prevent cross infection between rooms. All the inoculations were oral and performed using blunt feeding needles.

For the inoculations 5 birds in each group were marked with red fuchsin and inoculated at day 1 with $0.2 \mathrm{~mL}$ of an overnight culture of the $S$. Enteritidis pFlac:: $\operatorname{Tn} 3 \mathrm{Amp}^{\mathrm{R}} \mathrm{Rif}^{\mathrm{R}}$ strain. Immediately after the bacterial inoculation the treatment group were inoculated orally with $0.1 \mathrm{~mL}$ of antacid solution $\left(10 \% \mathrm{CaCO}_{3}\right)$ followed by $0.1 \mathrm{~mL}$ of phage MS2 suspension at $10^{11} \mathrm{PFU} / \mathrm{mL}$. Each bird in the control group was dosed with $0.2 \mathrm{~mL}$ of an antacid preparation only. Phage and antacid inoculation was repeated every day during the experiment. The water in the treatment group was also supplemented with MS2 phage at a final concentration of $10^{9} \mathrm{PFU} / \mathrm{mL}$.

On days 1, 2, 4, 6 and 8 post-infection all birds were cloacal-swabbed. Swabs were taken before each phage inoculation and placed in tubes containing $2 \mathrm{~mL}$ PBS. After brief mixing on a vortex mixer each swab was plated in a standard manner ${ }^{59}$ on a half Brilliant Green agar plate supplemented with rifampicin $(100 \mu \mathrm{g} / \mathrm{mL})$. The plates were incubated overnight at $37^{\circ} \mathrm{C}$ and scored for Salmonella presence as previously reported ${ }^{59}$. At day 4 post-infection 5 birds were sacrificed from each group and the caecal contents processed to enumerate the inoculated $S$. Enteritidis Rif ${ }^{\mathrm{R}}$. This was repeated at day 8 with the remaining birds from both groups. Decimal dilutions of caecal contents were plated on Brilliant Green agar plate supplemented with rifampicin $(100 \mu \mathrm{g} / \mathrm{mL})$. The numbers of lactose-positive, presumed plasmid-positive (Green) and lactose-negative, presumed plasmid-negative (Red) colonies were checked for each animal for both cloacal and caecal samples. To confirm antibiotic sensitivity 20 colonies of both colour types were plated onto Brilliant Green agar supplemented with rifampicin and ampicillin at a $100 \mu \mathrm{g} / \mathrm{mL}$. Those 40 colonies were also tested for phage susceptibility by spotting $10 \mu \mathrm{L}$ of MS2 phage $\left(10^{9} \mathrm{PFU} / \mathrm{mL}\right)$ onto lawns. Phage counts in caecal contents were determined on days 4 and 8 post-infection. For that, the initial $\mathrm{x} 10$ caecal dilutions were heated at $58^{\circ} \mathrm{C}$ for $30 \mathrm{~min}$ to kill the bacteria. Further decimal dilutions were made and $10 \mu \mathrm{L}$ aliquots were plated on lawns of $S$. Enteritidis P125109 pFlac::Tn3 (Amp ${ }^{\mathrm{R}} \mathrm{Rif}^{\mathrm{R}}$ ) growing on rifampicin LB agar $(100 \mu \mathrm{g} / \mathrm{ml})$.

Statistical analysis. Phage MS2 induced plasmid loss in vitro and Salmonella spread through the chicken flock were analysed using Fisher's exact test (Graphpad Prism, version 7.01). To evaluate the differences in plasmid presence and phage production, all bacterial and phage counts data were $\log _{10}$-transformed prior to statistical analysis. For data not following a normal distribution according to the Shapiro-Wilks normality test a Mann Whitney U test was done. (SPSS statistics 24 software, IBM). A two way ANNOVA with Bonferroni post-test was performed for samples following a normal distribution. 


\section{Data Availability}

The authors declare that the data supporting these findings is available within the paper or in its supplementary material.

\section{References}

1. Monroe, S. \& Polk, R. Antimicrobial use and bacterial resistance. Curr. Opin. Microbiol. 3, 496-501 (2000).

2. Ventola, C. L. The antibiotic resistance crisis: part 1: causes and threats. $P$ T 40, 277-83 (2015).

3. Bengtsson-Palme, J., Kristiansson, E. \& Larsson, D. G. J. Environmental factors influencing the development and spread of antibiotic resistance. FEMS Microbiol. Rev. 42, 68-80 (2018).

4. O’Neill, J. Antimicrobial Resistance: Tackling a crisis for the health and wealth of nations The Review on Antimicrobial Resistance Chaired. HM Gov. Trust b, 1-20 (2014).

5. Chen, L., Todd, R., Kiehlbauch, J., Walters, M. \& Kallen, A. Notes from the Field: Pan-Resistant New Delhi Metallo-Beta-LactamaseProducing Klebsiella pneumoniae - Washoe County, Nevada, 2016. MMWR. Morb. Mortal. Wkly. Rep. 66, 33 (2017).

6. Van Boeckel, T. P. et al. Global antibiotic consumption 2000 to 2010: An analysis of national pharmaceutical sales data. Lancet Infect. Dis. 14, 742-750 (2014)

7. Cabrera, A. S. et al. Rational use of antibiotics in the department of internal medicine from a university hospital: results of a pilot experience. Rev. Chil. infectología 29, 7-13 (2012).

8. Wendlandt, S. et al. Multidrug resistance genes in staphylococci from animals that confer resistance to critically and highly important antimicrobial agents in human medicine. Trends Microbiol. 23, 44-54 (2015).

9. European Food Safety Authority. The European Union summary report on antimicrobial resistance in antimicrobial resistance in zoonotic and indicator bacteria from humans, animals and food in the European Union in 2011. EFSA J. 11, 1-359 (2013).

10. Coates, A. R., Halls, G. \& Hu, Y. Novel classes of antibiotics or more of the same? Br. J. Pharmacol. 163, 184-194 (2011).

11. Liu, Y. Y. et al. Emergence of plasmid-mediated colistin resistance mechanism MCR-1 in animals and human beings in China: A microbiological and molecular biological study. Lancet Infect. Dis. 16, 161-168 (2016).

12. European Food Safety Authority. EU Summary report on antimicrobial resistance in zoonotic and indicator bacteria from humans, animals and food in 2013. EFSA J. 13,1-178 (2015).

13. Randall, L. P., Cooles, S. W., Osborn, M. K., Piddock, L. J. V. \& Woodward, M. J. Antibiotic resistance genes, integrons and multiple antibiotic resistance in thirty-five serotypes of Salmonella enterica isolated from humans and animals in the UK. J. Antimicrob. Chemother. 53, 208-216 (2004).

14. Williams Smith, H. \& Tucker, J. F. The effect on the virulence and infectivity of Salmonella Typhimurium and Salmonella Gallinarum of acquiring antibiotic resistance plasmids from organisms that had caused serious outbreaks of disease. J. Hyg. (Lond). 83, 305-317 (1979).

15. WHO. Global priority list of antibiotic-resistant bacteria to guide research, discovery, and development of new antibiotics. World Heal. Organ. 1-7 (2017).

16. WHO. Antimicrobial resistance. Global report on surveillance. Bull. World Health Organ. 61, 383-94 (2014).

17. Kutter, E. \& Sulakvelidze, A. Bacteriophages: biology and applications. (CRC Press, 2005).

18. Barrow, P. A. \& Soothill, J. S. Bacteriophage therapy and prophylaxis: rediscovery and renewed assessment of potential. Trends Microbiol. 5, 268-271 (1997).

19. Smith, H. W. \& Huggins, M. B. Successful treatment of experimental Escherichia coli infections in mice using phage: its general superiority over antibiotics. J. Gen. Microbiol. 128, 307-318 (1982).

20. Smith, H. W. \& Huggins, M. B. Effectiveness of phages in treating experimental Escherichia coli diarrhoea in calves, piglets and lambs. Microbiology 129, 2659-2675 (1983).

21. Barrow, P., Lovell, M. \& Berchieri, A. J. Use of lytic bacteriophage for control of experimental Escherichia coli septicemia and meningitis in chickens and calves. Clin. Diagn. Lab. Immunol. 5, 294-298 (1998).

22. Atterbury, R. J. et al. Bacteriophage therapy to reduce Salmonella colonization of broiler chickens. Appl. Environ. Microbiol. 73, 4543-9 (2007).

23. Loc Carrillo, C. et al. Bacteriophage therapy to reduce Campylobacter jejuni colonization of broiler chickens. Appl. Environ. Microbiol. 71, 6554-6563 (2005).

24. Carvalho, C. M. et al. The in vivo efficacy of two administration routes of a phage cocktail to reduce numbers of Campylobacter coli and Campylobacter jejuni in chickens. BMC Microbiol. 10, 232 (2010).

25. Coetzee, J. N., Bradley, D. E., Lecatsas, G., du Toit, L. \& Hedges, R. W. Bacteriophage D: an IncD group plasmid-specific phage. J. Gen. Microbiol. 131, 3375-3383 (1985).

26. Coetzee, J. N. \& Bardley, D. E. Janette Fleming; Laureen du Toit; Huges, M. H. R. Phage pilHa: a phage which adsorbs to IncHI and IncHII plasmid-coded pili. J. Gen. Microbiol. 131, 1115-1121 (1985).

27. Hayes, W. Genetics of bacteria and their viruses. (Blackwell Scientific Publications, Oxford, 1968).

28. Frost, L. S., Ippen-Ihler, K. \& Skurray, R. A. Analysis of the sequence and gene products of the transfer region of the F sex factor. Microbiol. Rev. 58, 162-210 (1994).

29. May, T. \& Okabe, S. Escherichia coli harboring a natural IncF conjugative F plasmid develops complex mature biofilms by stimulating synthesis of colanic acid and Curli. J. Bacteriol. 190, 7479-90 (2008).

30. Davis, J. E., Strauss, J. H. \& Sinsheimer, R. L. Bacteriophage MS2: another RNA phage. Science 134, 1427 (1961).

31. Smith, H. W. \& Linggood, M. A. Transfer factors in Escherichia coli with particular regard to their incidence in enteropathogenic strains. J. Gen. Microbiol. 62, 287-299 (1970).

32. Johnson, T. J. et al. In Vivo transmission of an IncA/C plasmid in Escherichia coli depends on tetracycline concentration, and acquisition of the plasmid results in a variable cost of fitness. Appl. Environ. Microbiol. 81, 3561-70 (2015).

33. Koraimann, G., Teferle, K., Markolin, G., Woger, W. \& Högenauer, G. The FinOP repressor system of plasmid R1: analysis of the antisense RNA control of traJ expression and conjugative DNA transfer. Mol. Microbiol. 21, 811-821 (1996).

34. Williams Smith, H. \& Tucker, J. F. The virulence of Salmonella strains for chickens: their excretion by infected chickens. J. Hyg. (Lond). 84, 479-88 (1980).

35. Ojala, V., Laitalainen, J. \& Jalasvuori, M. Fight evolution with evolution: plasmid-dependent phages with a wide host range prevent the spread of antibiotic resistance. Evol. Appl. 6, 925-32 (2013).

36. Jalasvuori, M., Friman, V.-P., Nieminen, A., Bamford, J. K. H. \& Buckling, A. Bacteriophage selection against a plasmid-encoded sex apparatus leads to the loss of antibiotic-resistance plasmids. Biol. Lett. 7, 902-5 (2011).

37. Smith, H. W. The transfer of antibiotic resistance between strains of Enterobacteria in chicken, calves and pigs. J. Med. Microbiol. 3 , 165-180 (1970).

38. De La Cruz, F., Garcilláon-Barcia, M. P. \& de Toro, M. Plasmid diversity and adaptation analyzed by massive sequencing of Escherichia coli plasmids. Microbiol. Spectr. 2 (2014).

39. Lanza, V. F. et al. Plasmid Flux in Escherichia coli ST131 sublineages, analyzed by plasmid constellation network (PLACNET), a new method for plasmid reconstruction from whole genome sequences. PLoS Genet. 10, e1004766 (2014).

40. Carattoli, A. et al. Identification of plasmids by PCR-based replicon typing. J. Microbiol. Methods 63, 219-228 (2005). 
41. Richmond, M. H., Guillespie, W. A. \& Anderson, J. D. Chemotherapy and antibiotic-resistance transfer between enterobacteria in the human gastro-intestinal tract. J. Med. Microbiol. 6, 461-473 (1973).

42. Smith, H. W. Transfer of antibiotic resistance from animal and human strains of Escherichia coli to resident E. coli in the alimentary tract of man. Lancet (London, England) 1, 1174-6 (1969).

43. Cheah, K.-C. \& Skurray, R. The F plasmid carries an IS3 insertion within finO. Microbiology 132, 3269-3275 (1986).

44. Fernandez-Lopez, R., de Toro, M., Moncalian, G., Garcillan-Barcia, M. P. \& de la Cruz, F. Comparative genomics of the conjugation region of F-like plasmids: Five Shades of F. Front. Mol. Biosci. 3, 71 (2016).

45. Costa, T. R. D. et al. Structure of the bacterial sex F pilus reveals an assembly of a stoichiometric protein-phospholipid complex. Cell 166, 1436-1444.e10 (2016).

46. Olsen, R. H., Siak, J. S. \& Gray, R. H. Characteristics of PRD1, a plasmid-dependent broad host range DNA bacteriophage. J. Virol. 14, 689-99 (1974).

47. Arutyunov, D., Rodriguez-Maillard, J. M. \& Frost, L. S. A PAS domain within F plasmid TraJ is critical for its function as transcriptional activator. Biochem. Cell Biol. 89, 396-404 (2011).

48. Zatyka, M. \& Thomas, C. M. Control of genes for conjugative transfer of plasmids and other mobile elements. FEMS Microbiol. Rev. 21, 291-319 (1998).

49. Barrow, P. A., Simpson, J. M. \& Lovell, M. A. Intestinal colonisation in the chicken by food-poisoning Salmonella serotypes; Microbial characteristics associated with faecal excretion. Avian Pathol. 17, 571-588 (1988).

50. Willetts, N. \& Skurray, R. Structure and function of the F factor and mechanism of conjugation. In Escherichia coli and Salmonella Typhimurium: Cellular and Molecular Biology. (eds Neidhart, F. C., Ingraham, J. L., Low, K. B., Magasanik, B., Schaechter, M. \& Umbarger, H.) 1110-1133 (American Society for Microbiology 1987).

51. Barrow, P. A. \& Lovell, M. A. Experimental infection of egg-laying hens with Salmonella Enteritidis phage type 4. Avian Pathol. 20, 335-348 (1991)

52. Halavatkar, H. \& Barrow, P. A. The role of a 54-kb plasmid in the virulence of strains of Salmonella Enteritidis of phage type 4 for chickens and mice. J. Med. Microbiol. 38, 171-176 (1993).

53. Sambrook, J., Fritsch, E. F. \& Maniatis, T. Molecular cloning: a laboratory manual. Mol. cloning a Lab. manual (1989).

54. Baig, A. et al. Biology and genomics of an historic therapeutic Escherichia coli bacteriophage collection. Front. Microbiol. 8, 1652 (2017).

55. Bankevich, A. et al. SPAdes: A new genome assembly algorithm and its applications to single-cell sequencing. J. Comput. Biol. 19, 455-477 (2012)

56. Camacho, C. et al. BLAST+: architecture and applications. BMC Bioinformatics 10, 421 (2009).

57. Thompson, J. D., Higgins, D. G. \& Gibson, T. J. CLUSTAL W: improving the sensitivity of progressive multiple sequence alignment through sequence weighting, position-specific gap penalties and weight matrix choice. Nucleic Acids Res. 22, 4673-80 (1994).

58. Price, M. N., Dehal, P. S. \& Arkin, A. P. FastTree: Computing large minimum evolution trees with profiles instead of a distance matrix. Mol. Biol. Evol. 26, 1641-1650 (2009).

59. Smith, H. W. \& Tucker, J. F. The effect of antibiotic therapy on the faecal excretion of Salmonella Typhimurium by experimentally infected chickens. J. Hyg. (Lond). 75, 275-92 (1975).

\section{Acknowledgements}

This work was supported by the UK Biotechnology and Biological Sciences Research Council grant BB/ M028399/1 Title: A bacteriophage-based approach to reducing infections caused by antibiotic resistant Escherichia coli. We are grateful for the help and support of staff at UNESP, Jaboticabal, São Paulo, Brazil.

\section{Author Contributions}

Joan Colom contributed to experimental design, performed in vitro/in vivo experiments and wrote the manuscript. Diego Batista, Lucas Marcelino, Marcela Rubio and Fernanda Barbosa contributed to in vivo experiments. Ying Tang, Siyang Liu, Fangzhong Yuan and Aouatif Belkhiri contributed to in vitro experimentation. Abiyad Baig did the genomic and phylogenetic analysis and contributed to in vitro work and manuscript preparation. Robert Atterbury supervised the project and contributed to manuscript writing. Angelo Berchieri supervised the project. Paul Barrow designed, conceptualized and supervised the project, also contributed to manuscript writing.

\section{Additional Information}

Supplementary information accompanies this paper at https://doi.org/10.1038/s41598-019-48483-9.

Competing Interests: The authors declare no competing interests.

Publisher's note: Springer Nature remains neutral with regard to jurisdictional claims in published maps and institutional affiliations.

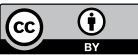

Open Access This article is licensed under a Creative Commons Attribution 4.0 International License, which permits use, sharing, adaptation, distribution and reproduction in any medium or format, as long as you give appropriate credit to the original author(s) and the source, provide a link to the Creative Commons license, and indicate if changes were made. The images or other third party material in this article are included in the article's Creative Commons license, unless indicated otherwise in a credit line to the material. If material is not included in the article's Creative Commons license and your intended use is not permitted by statutory regulation or exceeds the permitted use, you will need to obtain permission directly from the copyright holder. To view a copy of this license, visit http://creativecommons.org/licenses/by/4.0/.

(C) The Author(s) 2019 